MATEC Web of Conferences 31, 13001 (2015)

DOI: $10.1051 /$ matecconf/ 20153113001

(C) Owned by the authors, published by EDP Sciences, 2015

\title{
The research of creep in tunnel which surrounding rock is expansion
}

\author{
Junping Yang ${ }^{1,2}$, Shengnan $\mathrm{Li}^{1}$,Zhanyi Wang ${ }^{1}$ \\ 1 Guilin University of Technology, China \\ ${ }^{2}$ Guangxi Key Laboratory of Geomechanics and Geotechnical Engineering, China
}

\begin{abstract}
Selecting the highway tunnel project in GuangXi province as the experimental research object,using Matlab numerical analysis software to analyze the creep data fitting,this essay concludes that the Generalized kelvin model is proper for creep model.Through converting the creep formula of generalized kelvin model with the third creep formula of implicit creep of ANSYS finite element software implicit creep,it determines the creep model parameters. On this basis, by performing numerical simulations in four different construction methods on expansive surrounding rock tunnel,fill-section excavation, $\mathrm{CD}$ excavation,bench cut method and double-side-drift method applied,it researches properties of time-varying mechanical.The results shows that the construction mechanics characteristics of expansive surrounding rock tunnel are effected by time.The deformation of surrounding rock is enhanced with the growth of time,but it tends to be stabilized on the fourth day.Excavation ways have an effect on expansive surrounding rock mechanics. The more one-off excavation rock area digs, the more changes in stress,strain and creep change for the expansive surrounding rock.Among the four kinds of excavation methods,double-side-drift method has best stress form and minimum creep variable.
\end{abstract}

\section{Introduction}

Expansive surrounding rock is softening when it meets water.Accompanied with the expansion of the surrounding rock's volume, the strength ratio of surrounding rock reduces. In addition,because the excavation unloading making the surrounding rock wall's stress release and redistribution, it causes significant plastic deformation of surrounding rock and inflation pressure and relaxation pressure. At the same time, the expansive rock is swelling towards to the tunnel headroom, and when the shear stress of surrounding rock increases to a certain limit, the rock mass rheologic happens, thus the surrounding rock is squashed[1].There are some relationships between extrusion deformations with rheological ageing properties of rock material.It shows that the deformation of surrounding rock grows over time in the excavation, which is the creep phenomenon. Especially when the shear stress of surrounding rock reaches a certain limit,damage phenomenon appears immediately[2].Expansive rock is a kind of special soil which often brings serious difficulties and great disaster to the tunnel engineering construction.If the scientific researches and analysis on the time-varying mechanics are lacked in expansive rock tunnel's dynamic construction, the improper construction methods and inappropriate deformation control scheme will lead to disaster[3,7].However, most scholars at home and abroad use the simulation program to simulate the space effect in tunnel construction[8,11], and few people research the time-varying effect on expansive rock

\footnotetext{
${ }^{1}$ Shengnan li: 2561720910@qq.com
}

tunnel.So researches on creep properties of expansive rock tunnel have great significance for design and construction.For this reason, based on the expansive rock tunnel in YiHe highway large cross section in GuangXi province, this essay simulates the expansive rock tunnel's creep characteristics in the four kinds of excavation methods.By analyzing and contrasting the simulation results, it concludes the most suitable method for this project, thus provides the technical guidance for the tunnel construction.

\section{The general situation of project}

The tunnel is located in the BaiSe basin,most of the bedrock of Tunnel is exposed surface, and the part of bedrock was covered with diluvial clay.The total length of tunnel is 1217 meters, with the mileage from $\mathrm{K} 43+930$ to $\mathrm{K} 44+562$,it is located in the class IV surrounding rock.Tunnel section is designed width of $16.72 \mathrm{~m}$, clear height of $12.25 \mathrm{~m}$, with the excavation section area reach $167 \mathrm{~m} 2$, it's belongs to the category of large cross section tunnel.Tunnel excavation taking combined bolting and shotcrete in advance,grouting surrounding rock as the preliminary support, making sure the support of small catheter become effective before digging the hole,shoring shall be carried out immediately after excavation. The structure section of tunnel is shown in figure 1 . 


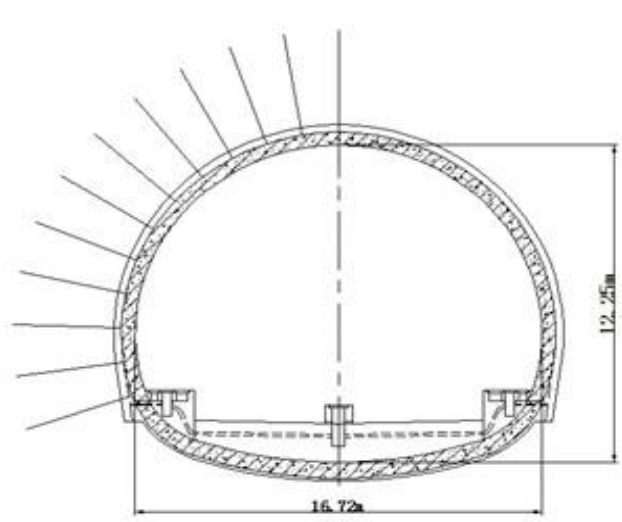

Figure 1.The section of swelling rock tunnel

\section{Create models}

\subsection{Selecting creep model}

Using the matlab numerical analysis software to fit the data of some creep models with viscoelastic, which results showed that the generalized kelvin model higher fitting precision and little error.Selecting the generalized kelvin model as the creep model.The Generalized kelvin model is shown in figure 2 .

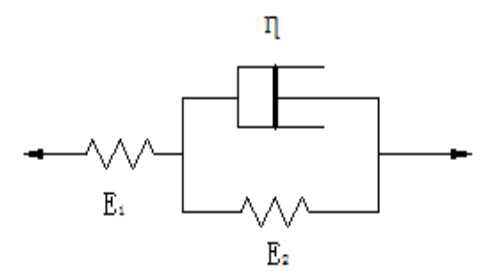

Figure2. The model of Generalized kelvin

Constitutive equation of Generalized kelvin model is shown as follows:

$$
\frac{\eta}{\mathrm{E}_{1}+\mathrm{E}_{2}} \dot{\sigma}+\sigma=\frac{\mathrm{E}_{1} \eta}{\mathrm{E}_{1}+\mathrm{E}_{2}} \dot{\varepsilon}+\frac{\mathrm{E}_{1} \mathrm{E}_{2}}{\mathrm{E}_{1}+\mathrm{E}_{2}} \varepsilon
$$

If the stress is constant in equation of Generalized kelvin model,the volumetric strain relations with time is shown as follows:

$$
\varepsilon=\frac{\sigma}{\mathrm{E}_{1}}+\frac{\sigma}{\mathrm{E}_{2}}\left[1-\exp \left(-\frac{\mathrm{E}_{2}}{\eta} t\right)\right]
$$

Using the Generalized kelvin curve model to fitting the data is shown in figure 3.

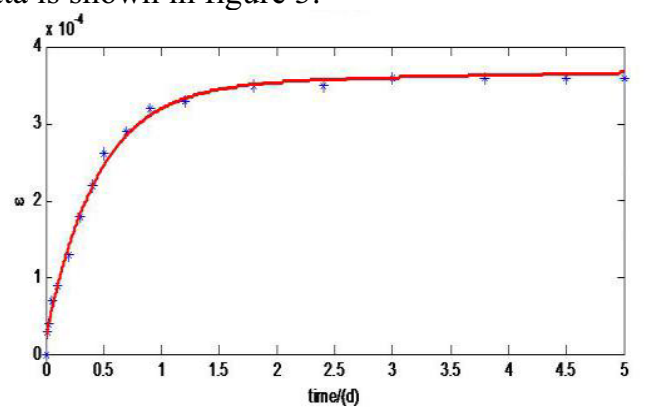

Figure.3 The creep curve fitting of Generalized kelvin model

\subsection{Selecting model parameters}

We can find that the Creep formula of generalized kelvin model is similar to third creep formula of implicit creep in ANSYS.So we select the implicit creep of ANSYS in the simulation.It's creep equation as Eq.3.In the Eq.3,r equal to Eq.4.Using the Eq4 substitute into Eq.3)and the result is shown as follow:

$$
\begin{gathered}
\dot{\varepsilon}=C_{1} \sigma^{C_{2}} r \bullet \exp (-r t) \\
r=C_{5} \sigma^{C_{3}} \bullet \exp \left(-C_{4} / \mathrm{T}\right) \\
\dot{\varepsilon}=C_{1} C_{5} \exp (-C / T) \sigma^{C_{2}} \sigma^{C_{3}} \exp \cdot \\
{\left[-C_{5} \sigma^{c_{3}} \exp \left(-C_{4} / T\right) t\right]}
\end{gathered}
$$

By doing derivation to creep Eq.2 of the generalized kelvin model,we can get the creep rate formula of Generalized kelvin is shown as follow:

$$
\dot{\varepsilon}=(\sigma / \eta) \bullet \exp \left(-\mathrm{E}_{2} t / \eta\right)
$$

Assuming that Eq.5 and Eq. 6 is one formula,it will attain this:

$$
\begin{aligned}
& 1 / \eta=C_{1} C_{5} \exp \left(-C_{4} / T\right) \sigma^{C_{3}} \\
& C_{2}=1 \\
& C_{3}=0 \\
& \mathrm{E}_{2} / \eta=C_{5} \sigma^{C_{3}} \exp \left(-C_{4} / T\right)
\end{aligned}
$$

$\mathrm{T}$ is the absolute temperature in the system of equation. $T$ The temperature of swelling soil surrounding rock is normal temperature, $20^{\circ} \mathrm{C}, \mathrm{T}=293 \mathrm{~K}$. Because the Eq.6 have more solution,we can suppose $\mathrm{C}_{4}=5$. By convering Eq.7 with the fitting creep curves of the generalized kelvin,we can attain a series of solutions: $\mathrm{C}_{1}=2.518 \times 10^{-9}, \mathrm{C}_{1}=1, \mathrm{C}_{4}=5$, $\mathrm{C}_{5}=1.699$.

\subsection{Model parameters and calculation assumptions of the finite element}

Using ANSYS to simulate the construction of tunnel at two-dimensional,and selecting the three times size of the tunnel as calculating width of the model, the boundary of surface is free ,the both sides and bottom edge is constrainted,which ignored the influence of ground water and solved the nonlinear creep equation in creep calculation via using the Newton-Raphson.In the calculation, we presume that the surrounding rock is elastic-viscosity material,the spatial effect is caused by tunnel excavation,the influence of tectonic stress and external water pressure is ignored.Only the gravity stress of surrounding rock is considered.Early and anchor supporting is considered isotropic material,and the secondary lining is not reflected in the selecting model elements are shown in table 1 . The calculation parameters of component are shown in table 2 . 
Table 1. Selecting model elements

\begin{tabular}{|c|c|c|c|}
\hline Element & $\begin{array}{c}\text { Surrounding } \\
\text { rock }\end{array}$ & Rock bolt & $\begin{array}{c}\text { Shotcreting } \\
\text { support }\end{array}$ \\
\hline Element & PLANE42 & LINK1 & BEAM3 \\
\hline
\end{tabular}

Table.2 Component calculation parameter

\begin{tabular}{|c|c|c|c|}
\hline Item & $\begin{array}{c}\text { elasticity } \\
\text { modulus(MPa) }\end{array}$ & $\begin{array}{c}\text { Poisson's } \\
\text { ratio }\end{array}$ & $\begin{array}{c}\text { Density } \\
\left(\mathrm{kg} / \mathrm{m}^{3}\right)\end{array}$ \\
\hline Surrounding & $3.9 \times 10^{4}$ & 0.2 & 2041 \\
\hline Support & $2.9 \times 10^{4}$ & 0.167 & 2347 \\
\hline Rock bolt & $1.7 \times 10^{5}$ & 0.3 & 7959 \\
\hline
\end{tabular}

\section{The calculation results and analysis}

Selecting vault, hance, arch springing and tensile as the research target,where we analysis stress distribution and time-varying effect of surrounding rock in the excavation.A represent surrounding rock in the vault.B,C represent surrounding rock in the hance.D,E represent surrounding rock in the arch springing.F,G represent surrounding rock in the tensile.a,b,c,d represent whole section excavation method,CD method,the benching tunneling method,double-side-drift method sequential.the later paper don't description.Because of the limitation of space,we just list the creep curve of point A (the dome of the tunnel) in the 4 different excavation method as show figures 4 through 7.In the 4 different excavation method, we summarize the stress of surrounding rock, horizontal displacement, vertical displacement, the stress of the anchor and shotcrete in table 3 through 5.The positive (negative) represent stress to pull (pressure) stress.

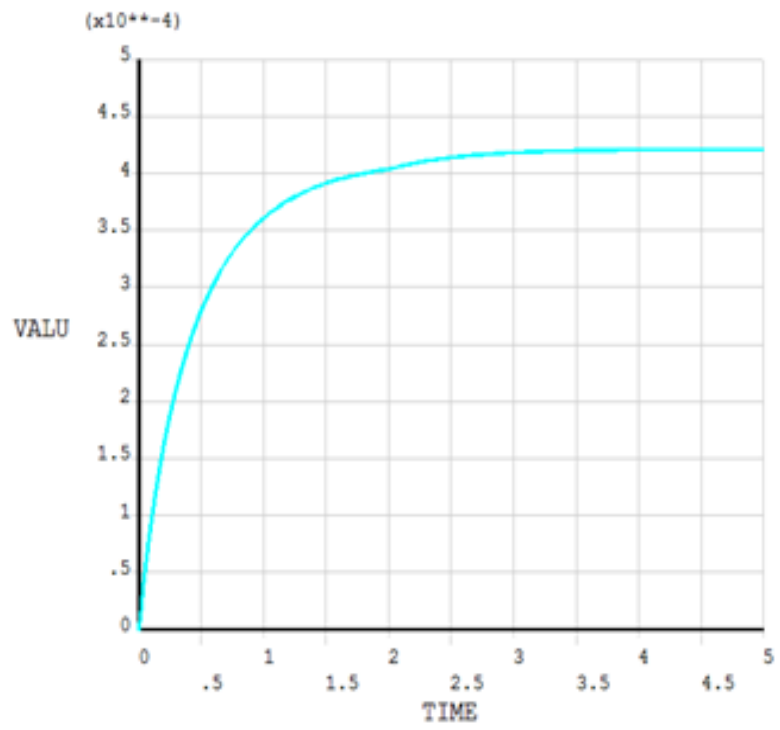

Figure.4 Creep curve in the vault of The whole ection excavation method $(5 \mathrm{~d})$

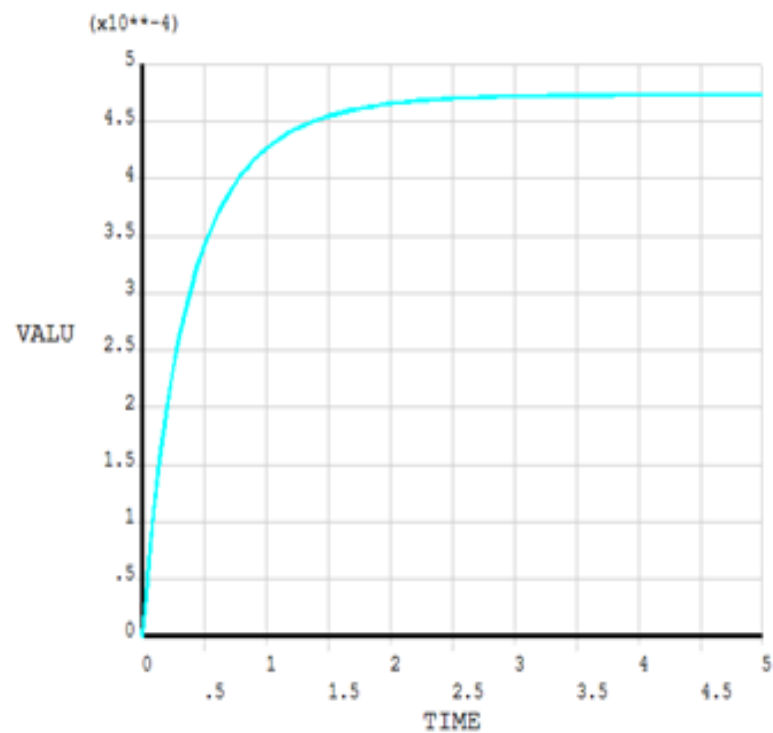

Figure.5 Creep curve in the vault of the CD method(5d)

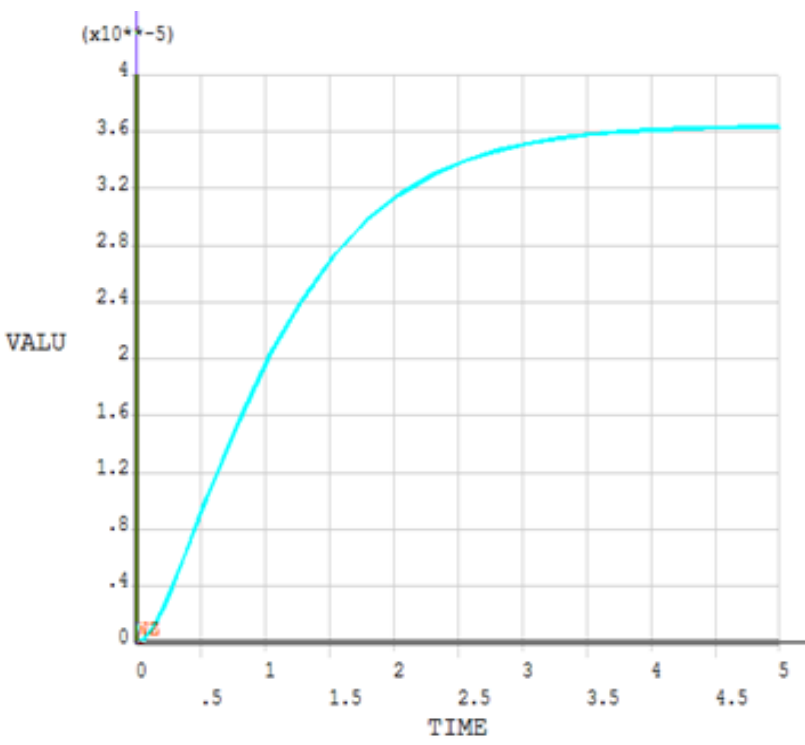

Figure.6Creep curve in the vault of the steps method(5d)

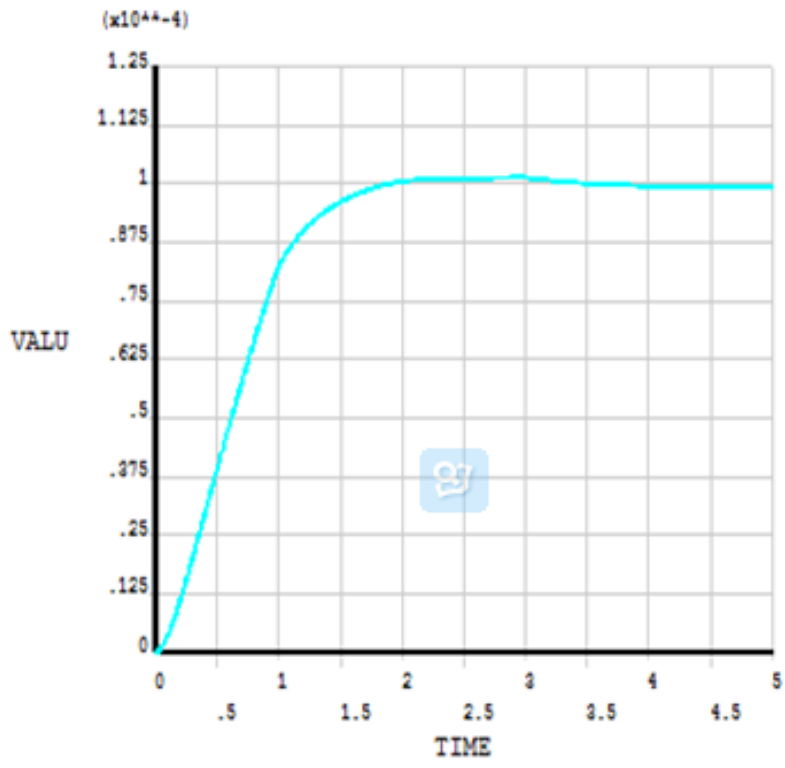

Figure.7Creep curve in the vault of the double wall pilot tunnel method(5d) 
Table.3 The calculation results of the maximum principal stress in different excavation model

\begin{tabular}{|c|c|c|c|c|c|c|c|}
\hline \multirow{2}{*}{ Method } & \multirow{2}{*}{ Step } & \multicolumn{6}{|c|}{ Maximum principal stress(10-2 MPa) } \\
\cline { 2 - 8 } & & A & B & C & D & E & F \\
\hline \multirow{3}{*}{ a } & 1 & 44 & 68 & 67 & 78 & 78 & 85 \\
\cline { 2 - 9 } & 2 & 68 & 81 & 82 & 95 & 95 & 150 \\
\hline \multirow{4}{*}{ b } & 1 & 52 & 7 & 7 & 84 & 83 & 85 \\
\cline { 2 - 9 } & 2 & 49 & 73 & 73 & 93 & 93 & 23 \\
\cline { 2 - 9 } & 3 & 57 & 59 & 57 & 82 & 83 & 95 \\
\hline \multirow{4}{*}{$\mathrm{c}$} & 1 & 45 & 64 & 64 & 72 & 7 & 72 \\
\cline { 2 - 9 } & 2 & 35 & 53 & 5 & 55 & 6 & 41 \\
\cline { 2 - 9 } & 3 & 42 & 57 & 53 & 81 & 85 & 9 \\
\hline \multirow{4}{*}{$\mathrm{d}$} & 1 & 54 & 71 & 72 & 82 & 82 & 85 \\
\cline { 2 - 8 } & 2 & 61 & 68 & 53 & 86 & 87 & 100 \\
\cline { 2 - 8 } & 3 & 63 & 5 & 53 & 8 & 82 & 100 \\
\cline { 2 - 8 } & 4 & 43 & 61 & 64 & 92 & 94 & 29 \\
\hline & 5 & 43 & 61 & 65 & 91 & 94 & 23 \\
\hline
\end{tabular}

The negative (positive) represent stress to pressure (pull)stress.

Table.4 The calculation results of horizontal displacement in different excavating model

\begin{tabular}{|c|c|c|c|c|c|c|c|}
\hline \multirow{2}{*}{ Method } & \multirow{2}{*}{ step } & \multicolumn{6}{|c|}{ Vertical displacement(mm) } \\
\hline & & A & B & $\mathrm{C}$ & $\mathrm{D}$ & $\mathrm{E}$ & $\mathrm{F}$ \\
\hline \multirow{3}{*}{$\mathrm{a}$} & 1 & 34 & 32 & 32 & 30 & 30 & 27 \\
\hline & 2 & 160 & 148 & 146 & 134 & 135 & 87 \\
\hline & Finish & 126 & 116 & 114 & 104 & 105 & 60 \\
\hline \multirow{4}{*}{$\mathrm{b}$} & 1 & 23 & 20 & 20 & 18 & 18 & 18 \\
\hline & 2 & 28 & 22 & 22 & 19 & 19 & 9 \\
\hline & 3 & 43 & 30 & 29 & 18 & 19 & 2 \\
\hline & Finish & 20 & 10 & 9 & 0 & 1 & 20 \\
\hline \multirow{4}{*}{$\mathrm{c}$} & 1 & 20 & 18 & 18 & 16 & 16 & 15 \\
\hline & 2 & 29 & 21 & 21 & 18 & 18 & 10 \\
\hline & 3 & 25 & 19 & 19 & 17 & 17 & 8 \\
\hline & Finish & 5 & 1 & 1 & 1 & 1 & 7 \\
\hline \multirow{6}{*}{$\mathrm{d}$} & 1 & 23 & 20 & 20 & 18 & 18 & 17 \\
\hline & 2 & 24 & 21 & 21 & 18 & 18 & 18 \\
\hline & 3 & 25 & 22 & 22 & 18 & 18 & 18 \\
\hline & 4 & 28 & 22 & 22 & 19 & 19 & 13 \\
\hline & 5 & 28 & 22 & 22 & 19 & 19 & 12 \\
\hline & Finish & 5 & 2 & 2 & 1 & 1 & -5 \\
\hline
\end{tabular}

The negative(positive) represent vertical displacement to up (down) in the table.
Table.5 The results of anchor,supporting force and surrounding rock creep contrast with the different of excavation model

\begin{tabular}{|c|c|c|c|c|}
\hline Excavation method & $\mathrm{a}$ & $\mathrm{b}$ & $\mathrm{c}$ & $\mathrm{d}$ \\
\hline $\begin{array}{c}\text { Maximum axial force } \\
\text { position }\end{array}$ & $\mathrm{A}$ & $\mathrm{B}$ & $\mathrm{C}$ & $\mathrm{D}$ \\
\hline $\begin{array}{c}\text { Anchor maximum axial } \\
\text { force }\end{array}$ & $\begin{array}{c}17 \\
\mathrm{kN}\end{array}$ & $\begin{array}{c}12.2 \\
\mathrm{kN}\end{array}$ & $\begin{array}{c}5.8 \\
\mathrm{kN}\end{array}$ & $\begin{array}{c}10.5 \\
\mathrm{kN}\end{array}$ \\
\hline $\begin{array}{c}\text { Supporting maximum } \\
\text { bending moment }\end{array}$ & $\mathrm{A}$ & $\mathrm{B}$ & $\mathrm{C}$ & $\mathrm{D}$ \\
\hline $\begin{array}{c}\text { Supporting maximum } \\
\text { bending moment value }\end{array}$ & $\begin{array}{c}278 \\
\mathrm{kN} \\
\mathrm{m}\end{array}$ & $\begin{array}{c}2340 \\
\mathrm{kN} \\
\mathrm{m}\end{array}$ & $\begin{array}{c}894 \\
\mathrm{kN} \\
\mathrm{m}\end{array}$ & $\begin{array}{c}1320 \\
\mathrm{kN} \\
\mathrm{m}\end{array}$ \\
\hline $\begin{array}{c}\text { Supporting maximum } \\
\text { axial force position }\end{array}$ & $\mathrm{A}$ & $\mathrm{B}$ & $\mathrm{C}$ & $\mathrm{D}$ \\
\hline $\begin{array}{c}\text { Supporting maximum } \\
\text { axial force value }\end{array}$ & $\begin{array}{c}1530 \\
\mathrm{kN}\end{array}$ & $\begin{array}{c}2240 \\
\mathrm{kN}\end{array}$ & $\begin{array}{c}1530 \\
\mathrm{kN}\end{array}$ & $\begin{array}{c}1250 \\
\mathrm{kN}\end{array}$ \\
\hline $\begin{array}{c}\text { Anchor maximum } \\
\text { shearing force position }\end{array}$ & $\mathrm{A}$ & $\mathrm{B}$ & $\mathrm{C}$ & $\mathrm{D}$ \\
\hline $\begin{array}{c}\text { Anchor maximum } \\
\text { shearing force value }\end{array}$ & $\begin{array}{c}2740 \\
\mathrm{kN}\end{array}$ & $\begin{array}{c}1550 \\
\mathrm{kN}\end{array}$ & $\begin{array}{c}1100 \\
\mathrm{kN}\end{array}$ & $\begin{array}{c}1570 \\
\mathrm{kN}\end{array}$ \\
\hline $\begin{array}{c}\text { Creep s maximum } \\
\text { value position }\end{array}$ & $\mathrm{A}$ & $\mathrm{B}$ & $\mathrm{C}$ & $\mathrm{D}$ \\
\hline $\begin{array}{c}\text { Creep maximum value } \\
\mathrm{mm}\end{array}$ & $\begin{array}{c}1.0 \\
\mathrm{~mm}\end{array}$ & $\begin{array}{c}0.12 \\
\mathrm{~mm}\end{array}$ & $\begin{array}{c}0.35 \\
\mathrm{~mm}\end{array}$ \\
\hline
\end{tabular}

1.From the view of stress:the maximum principal stress of CD method,bench cut method and both side drift method are not different to each other.But maximum principal stress of full-face tunneling method is greater than the other three excavation method.It is bad for excavation of swelling wall rock tunnel.In additional, full face excavation method is single excavation, which the excavation area is larger in terms of an excavation. What's more,the surrounding rock is disturbanced obviously,and it makes the maximum principal stress changed larger.Instead, both side drift method breaks down the section of tunnel into four parts, which excavation area is reduced greatly in an excavation. The maximum principal stress rate turns lower between adjacent excavation steps, it is better to control construction. The both side drift method is the best construction scheme in the view of stress.

2.From the view of strain and creep:In the process of construction, different excavation method changed the boundary conditions of surrounding rock stress, which horizontal displacement of full face excavation method are much higher than other three kinds of schemes, and its variable displacement is larger in adjacent construction step.In additional,through researching the creep curve of excavation in 5 days,we can find that the creep variable of full face excavation method is the largest(The time for each step of the excavation is different, but the total time of construction are five days).In the other three 
excavation method,the subsidence displacement of CD and both side drift method are more appropriate the construction of expansive surrounding rock of the tunnel in the view of strain and creep.

3.From the view of the force at the anchor and shotcreting:the axial force of the anchor of CD method and both side drift method is larger,but they are in the normal range.Shotcrete supporting axial force, bending moment and shear force of CD method is smaller both side drift method.So the CD method is the best way to excavation.

\section{Conclusion}

1.The construction mechanics of expansion surrounding rock tunnel has time-varying characteristics, the excavation break the stress distribution of surrounding rock, and it makes the creep change.With the different excavation method,the stress distribution, Creep variable and ,the location of the maximum creep value are different in the surrounding rock tunnel.

2.In the four types of method, the variation of creep is decreasing,and the creep is basic to achieve stability on the fourth day.they are belonging to the non-decaying creep.

3. With the comprehensive consideration,we contrast the stress, deformation, creep and bolt and force of the support, and the result is that the both side drift method is the best construction to the expansive surrounding rock tunnel. method is larger,it is up to $20 \mathrm{~mm}$. So bench cut method

\section{Acknowledgments}

Special thanks to Natural Science Foundation of China (NSFC),study Time-varying mechanics of the expansion surrounding rock tunnel when it constructed in the hot and rainy environment(51368014); and Natural Science Foundation of GuangXi,analyse and control dynamic response of large-section tunnel when it constructed and operated in complicated condition (2011GXNSFA018023)

\section{References}

1. G.Barla,Int.Soc.Rock Mech.News J 2, 45 (1995)

2. T.T.Lim,H.Rahardjo,M.F.Chang,D.G.Fredlund,Can. Geotech. J 33, 628 (1996)

3. H.H.Einstein,Int.J. Rock.Meth..Minsci 3, 420 (1989)

4. A.A.Al-Rawas,Eng.Geol 53, 329 (1999)

5. H.H. Einstein,Tunn.Undergr.Sp.Tech 15, 20(2000)

6. Z.A.Erguler,R.Ulusay,Clay.Eng.Geol 67, 338( 2003)

7. P.C.Kariuki,F.vander Meer,Int.J.Appl.Earth.Obs 4, $235(2003)$

8. C.F.Lee,C.F.Wang,Z.F.Yang,Tunn.Undergr.Sp.Tech 11, 450 (1996)

9. F.T.Madsen, Int.J. Rock.Meth..Minsci 36, 301 (1999)

10. P.Wersina,E.Curtib,C.A.J.Appelo,Appl.Clay.Sci 26, 255(2004)

11. S.Batfdis,A.C.Lumsden,N.R.Barton,Int.J.rock.Meth. Minsci 18, 18(1981) 